\title{
Greywater Quality Changes in Laboratory Scale Vegetative Biofiltration Prototypes
}

\author{
Rezaul K. Chowdhury, ${ }^{1,2}$ Jameelu S. Abaya, ${ }^{2}$ Taoufik Tsiksi ${ }^{2}$ and Mohamad M. Mohamed ${ }^{2}$ \\ ${ }^{1}$ University of Southern Queensland, Toowoomba, Australia; ${ }^{2}$ United Arab Emirates University, Al Ain, United Arab Emirates.
}

\begin{abstract}
Greywater recycling and reuse is becoming a popular choice in many water-scarce regions. Greywater is the largest component of domestic indoor wastewater. However, in many arid regions, including the United Arab Emirates (UAE), this unconventional resource is under-utilized. Although, traditionally, a biofiltration system operates using stormwater, findings have shown that the operation of biofiltration systems in arid regions can be successful using greywater. This research endeavors to assess how the quality of the effluent from a biofiltration system changes with different vegetation, both native and introduced to the arid region (UAE). The prototype biofilters, planted with twelve ornamental plant species, were irrigated daily with an equal amount of synthetic greywater and the water quality parameters were monitored on a weekly basis. Analysis of variance (ANOVA) was performed in order to statistically evaluate the consistency of results between the three replicates of each of the twelve species and, subsequently, the variation of treatment effectiveness among the twelve species with respect to eight water quality parameters. Most of the plants show a high degree of consistency between replicates; however, significant differences were observed across the selected plant species. The species Ficus nitida and Canna indica performed well in reducing $\mathrm{pH}$. Except in the earlier stages of the experiment, all the systems were found to reduce turbidity by almost $100 \%$. Overall, it was observed that Ficus nitida, Canna indica and Pennisetum setaceum performed well to improve greywater quality in the biofiltration columns.
\end{abstract}

\section{Introduction}

Greywater reuse is becoming a popular practice in water-scarce countries. Greywater is comparatively less polluted than blackwater and has the potential to be reused for irrigation and non-potable consumption. Chowdhury et al. (2015) estimated that in arid climates (such as United Arab Emirates, UAE), average greywater generation is $\sim 190 \mathrm{~L} /$ capita/d, and about $50 \%$ of this can be harvested without affecting downstream sewer flow (Chowdhury and Rajput 2017). Among different greywater treatment systems (Li et al. 2009), a vegetated treatment system is considered to be one of the most environmentally sustainable and cost effective options (Prodanovic et al. 2017). Several studies have explored the suitability of constructed wetlands in treating urban wastewater, greywater and stormwater (Li et al. 2003; Paulo et al. 2013). A comprehensive review of vegetative treatment systems (constructed wetlands) is provided by Vymazal (2011a). Li et al. (2003) reported that a combination of processes such as treating greywater through constructed wetlands and subsequently through a titanium dioxide based photocatalytic oxidation process (short irradiation time) can meet the European bathing water quality requirements and can directly be reused for non-potable purposes. Recently, a living wall system (ornamental plants grown in a sand filter on the side of a building) was investigated for greywater treatment by Fowdar et al. (2017). While they found that some ornamental plants (e.g. Carex appressa R.Br., Canna spp., Lonicera japonica Thunb.) performed well in reducing greywater nitrogen levels (more than 80\%), phosphorus removal efficiency was highly wariable (13\% to 99\%). Ornamental plants such as Carex appressa R.Br. and Canna spp. were found to be the best performing plants in their case study location (Melbourne, Australia).

Plants in vegetative systems perform several functions related to the treatment processes. Vymazal (2011b) provided a comprehensive description of the roles of plants in vegetative treatment systems (constructed wetlands). Langergraber (2005) estimated a potential nutrient uptake of about $1.9 \%$ of the influent nitrogen and phosphorus load in wastewater treatment in a constructed wetland, whereas for lower loaded systems (greywater treatment) a significantly higher (46\%) nitrogen uptake rate was observed. The roots of vegetation in a biofiltration system support a varied microbiota, especially bacteria and fungi, which affects the characteristics of the rhizosphere and thus improves the plants' nutrient intake and respiration as well as the hydraulic conductivity of the soil (Wong 2006; Blick et al. 2004). The biological processes responsible for pollutant removal in the root zone constitute the phytoremediation (uptake by plants) and bioremediation (microbial conversion) processes (Davis et al. 2006). In addition, the vegetation helps to mitigate the urban heat island

Chowdhury, Rezaul K., Jameelu S. Abaya, Taoufik Tsiksi and Mohamad M. Mohamed. 2017. Greywater Quality Changes in Laboratory Scale

Vegetative Biofiltration Prototypes. Journal of Water Management Modeling 26:C434. https://doi.org/10.14796/JWMM.C434

(c) CHI 2017. www.chijournal.org ISSN 2292-6062. 
effects through provision of direct shading and carbon sequestration and by enhancing urban biodiversity (Endreny and Collins 2009; Kazemi et al. 2009). Biofiltration media play a critical role in vegetated systems as well. They provide physical support for plants and facilitate removal processes for pollutants such as sediment, phosphorus and heavy metals (Prodanovic et al. 2017). Thus the selection of plants is considered a very important issue in good design of vegetative treatment systems.

A biofiltration system is an engineered system conventionally designed to improve stormwater quality in urban areas. The systems are used in residential, commercial, public and industrial areas to drain water from gardens, roofs, parking lots, footpaths and roadways (Blick et al. 2004). Physically, a biofiltration system is a shallow landscaped depression area which is typically underdrained. It normally relies on engineered soils, enhanced vegetation, and filtration to remove pollutants and to reduce urban runoff downstream (Woods-Ballard et al. 2007). The pollutants can be suspended solids, nutrients, metals, hydrocarbons or microorganisms. A biofiltration system is designed as a multi-stage and multi-functional system that reduces the rate of peak runoff and facilitates stormwater infiltration (Blick et al. 2004). The excess stormwater from an extreme event is drained through an overflow system connected to a stormwater drainage network. In a biofiltration system, some portions of the runoff are lost through evaporation and plant transpiration mechanisms (Woods-Ballard et al. 2007). Architecturally, a biofiltration system has the flexibility to fit into the urban landscape to provide an aesthetic environment even in highly impervious areas. However, in a poorly managed landscape or on a steep slope it is susceptible to clogging.

The main component of a biofiltration system is the engineered soil, with a known hydraulic conductivity, filled into a trench to filter water. The infiltration process enhances the degree of treatment of the system (Wong 2006). The upper section of the soil is the mulch or organic area. It assists infiltration and creates a favorable environment for the microorganisms that break down hydrocarbons and organic matters. The mulch layer is on top of a planting soil layer, which also supports infiltration and serves as a planting medium. In particular, the clay component provides a good adsorption medium for hydrocarbons, heavy metals and nutrients (Henderson et al. 2007). The lower section, which is also the largest component of the system, is the sand bed. It is the medium for drainage and for aerobic reactions. It provides the final and refining treatment in the system. The filtered water usually drains from the biofiltration system through an underdrain system.

Greywater treatment through biofiltration systems is a relatively new concept in urban water management. A previous study (Chowdhury 2015) experimentally showed that biofiltration systems are significantly effective in treating greywater for irrigation end use in the UAE. In arid regions, where rainfall and runoff are not abundant urban water resources, greywater biofiltration systems can be adopted for water conservation practices.
However, the selection of plants and their performance in the greywater biofiltration system has not yet been investigated in arid regions. In order to investigate this, twelve ornamental plant species, native or introduced to UAE, were planted in 36 biofiltration columns (three plants for each of twelve species) and the water quality of effluents from the columns was monitored. The selected plant species are shown in Table 1. The aim of the study was to evaluate the performance of different plants in greywater biofiltration columns. The water quality parameters observed were $\mathrm{pH}$, oxidation reduction potential (ORP), turbidity (TB), salinity (SL), electrical conductivity (EC), dissolved oxygen (DO) and total dissolved solids (TDS).

Table 1 Plant species used in the experiment.

\begin{tabular}{lc}
\hline \multicolumn{1}{c}{ Plant Species } & Abbreviation \\
\hline Alternanthera ficoidea (L.) P. Beauv. & Alt \\
Canna indica L. & Can \\
Dodonaea viscosa (L.) Jacq. & Dod \\
Ficus nitida Hook. ex Miq. & Fic \\
Hibiscus rosa-sinensis L. & Hib \\
Ixora coccinea L. & Ixo \\
Jasminum sambac L. Aitum & Jas \\
Lantana camara L. & Lan \\
Pennisetum setaceum (Forssk.) Chiov. & Pen \\
Tradescantia spathacea Sw., & Rho \\
also known as Rhoeo discolor (L'Her.) Hance & Vin \\
Vinca rosea L. & Vit \\
Vitex agnus-castus L. &
\end{tabular}

\section{Materials and Methods}

The study area is located in the city of Al Ain, UAE at $24.2075^{\circ} \mathrm{N}$, $55.74472^{\circ} \mathrm{E}$. The region is characterized by an arid desert climate having an average annual temperature in the range $13^{\circ} \mathrm{C}$ to $44^{\circ} \mathrm{C}$, which occasionally rises above $46^{\circ} \mathrm{C}$ and falls below $10^{\circ} \mathrm{C}$. The warmest season is between May and September with minimum temperature as high as $31^{\circ} \mathrm{C}$ and average temperature above $40^{\circ} \mathrm{C}$. The probability of rainfall is very small and rainfall is scattered over the year. The average annual rainfall is $96 \mathrm{~mm}$ to $120 \mathrm{~mm}$, while the relative humidity typically ranges from $13 \%$ (very dry) to $88 \%$ (very humid) over the course of the year, sometimes dropping below $7 \%$ and rising as high as $99 \%$. Over the course of a year, typical wind speeds vary from $1 \mathrm{~m} / \mathrm{s}$ (light air) to $8 \mathrm{~m} / \mathrm{s}$ (fresh breeze) and rarely exceed $11 \mathrm{~m} / \mathrm{s}$ (https://weatherspark.com/).

The 36 biofiltration columns were constructed and 3 plants for each of 12 species were planted. The length and diameter of the columns were $60 \mathrm{~cm}$ and $15.8 \mathrm{~cm}$ respectively (Figure 1). The effective length was $54 \mathrm{~cm}$, as $6 \mathrm{~cm}$ was left unfilled for the temporary storage of irrigation water. A drainage layer of $5.3 \mathrm{~cm}$ was provided at the bottom of the columns; it was filled with aggregate of size $2 \mathrm{~mm}$ to $5 \mathrm{~mm}$. On top of the drainage layer, a 
transition layer $8 \mathrm{~cm}$ deep was provided, filled with soil of grain size in the range $0.50 \mathrm{~mm}$ to $2 \mathrm{~mm}$. The topmost layer was the root growth layer (filter media) $40 \mathrm{~cm}$ deep, which included a well-graded soil from $75 \mu \mathrm{m}$ to $4.75 \mathrm{~mm}$ in grain size, composed of sand (25\%), compost (20\%), gravel of size $0.5 \mathrm{~mm}$ to $2 \mathrm{~mm}$ (35\%) and gravel of size $2 \mathrm{~mm}$ to $5 \mathrm{~mm}$ (20\%). The columns (Figure 2) were constructed using polyvinyl chloride (PVC) pipe and a faucet was fitted at the bottom in order to drain effluent from the column. The system was built in multiple layers in order to avoid the toxic effects on plants of hydrogen sulfide and other substances released in the anaerobic breakdown of organic matters that are typically found in a single layer biofiltration system (Trowsdale and Simcock 2011). The selected plants (shown in Table 1 above) used in the experiment are typical ornamental plants found in homes and gardens in UAE. They have high to moderate tolerance of drought and heat.

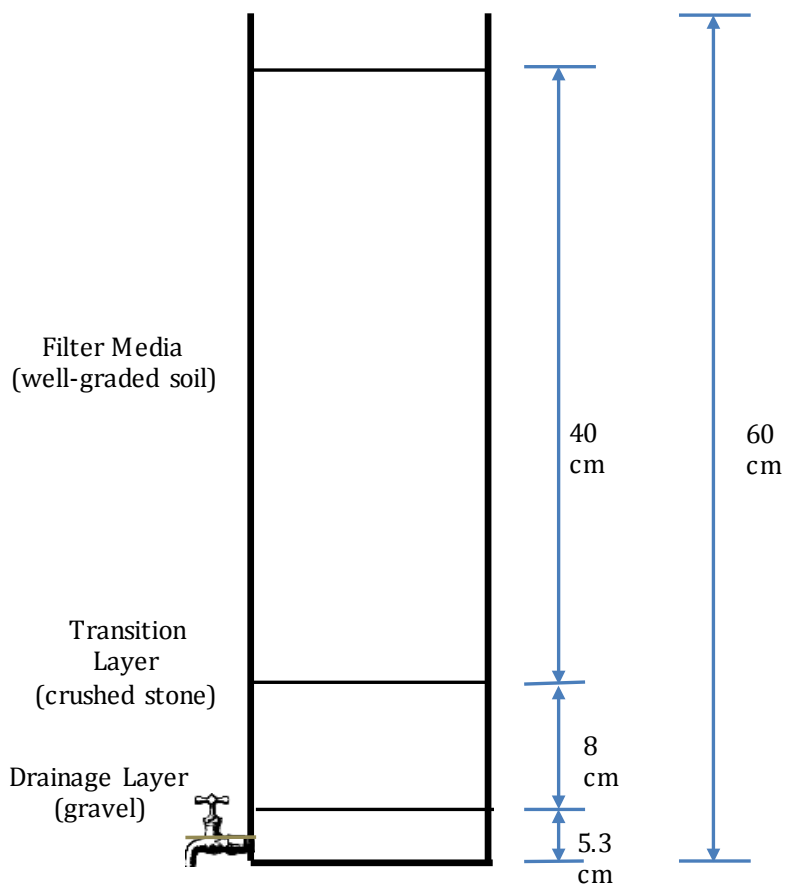

Figure 1 Schematic view of biofiltration column.

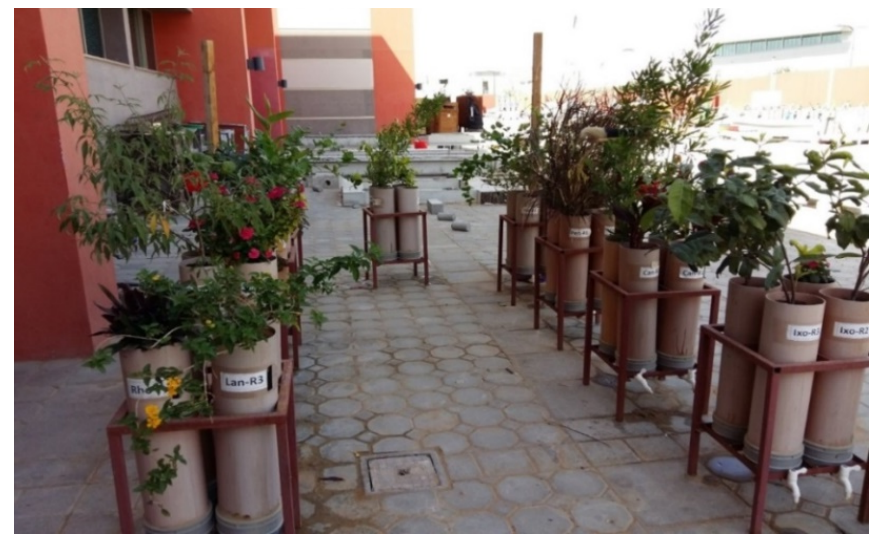

Figure 2 The 36 biofiltration columns.
The columns were irrigated using municipal (desalinated) water for two months, 2015-09-2015-10, to allow the plants to acclimatize to their new environment. Subsequently, and depending on the weather, a measured quantity of synthetic greywater ( $6.5 \mathrm{~mm}$ to $25.5 \mathrm{~mm}$ ) was applied uniformly to all the columns on a daily basis. However, the effluent samples were collected on a weekly basis. The column study was conducted considering a batch mode of reaction without a retention or detention time.

The concentrations of water quality parameters in the synthetic greywater are given in Table 2. The experiment was conducted for 6 months (2015-11-2016-04) and the columns were kept in outdoors. The water quality parameters were monitored on a weekly basis using a Horiba U-52 Multiparameter Water Quality Probe. In every reading, each sample was measured 7 times at intervals of $1 \mathrm{~min}$ and the average of the last 3 readings was used in the data analyses. During the growth period of the plants, the following fertilizers were applied equally 3 times to each column: NPK (nitrogen, phosphorus and potassium), $1.53 \mathrm{~g} / \mathrm{mL}$; magnesium sulfate, $\mathrm{MgSO}_{4^{\prime}} 0.83 \mathrm{~g} / \mathrm{mL}$; and calcium nitrate, $\mathrm{CaNO}_{3}, 0.55 \mathrm{~g} / \mathrm{mL}$.

Table 2 Concentration of water quality parameters in synthetic greywater.

\begin{tabular}{|c|c|c|c|c|c|c|c|}
\hline Week & $\mathrm{pH}$ & $\begin{array}{l}\text { ORP } \\
\mathrm{mV}\end{array}$ & $\begin{array}{c}\mathrm{EC} \\
\mathrm{mS} / \mathrm{cm} \\
\end{array}$ & $\begin{array}{c}\text { TB } \\
\text { NTU } \\
\end{array}$ & $\begin{array}{c}\mathrm{D} 0 \\
\mathrm{mg} / \mathrm{L}\end{array}$ & $\begin{array}{l}\text { TDS } \\
\mathrm{g} / \mathrm{L}\end{array}$ & $\begin{array}{c}\mathrm{SL} \\
\mathrm{ppt}\end{array}$ \\
\hline 1 & 8.41 & 366 & 0.27 & 0.000 & 5.16 & 0.18 & 0.10 \\
\hline 2 & 9.39 & 93 & 0.43 & 61.27 & 3.86 & 0.28 & 0.20 \\
\hline 3 & 9.39 & 93 & 0.43 & 61.27 & 3.86 & 0.28 & 0.20 \\
\hline 4 & 8.72 & 64 & 0.48 & 34.20 & 3.96 & 0.31 & 0.20 \\
\hline 5 & 8.72 & 64 & 0.48 & 34.20 & 3.96 & 0.31 & 0.20 \\
\hline 6 & 8.26 & 112 & 0.45 & 14.13 & 6.86 & 0.29 & 0.20 \\
\hline 7 & 8.26 & 112 & 0.45 & 14.13 & 6.86 & 0.29 & 0.20 \\
\hline 8 & 8.26 & 112 & 0.45 & 14.13 & 6.86 & 0.29 & 0.20 \\
\hline 9 & 7.78 & 124 & 0.51 & 38.90 & 4.72 & 0.32 & 0.20 \\
\hline 10 & 7.78 & 124 & 0.51 & 38.90 & 4.72 & 0.32 & 0.20 \\
\hline 11 & 7.78 & 124 & 0.51 & 38.90 & 4.72 & 0.32 & 0.20 \\
\hline 12 & 7.78 & 124 & 0.51 & 38.90 & 4.72 & 0.32 & 0.20 \\
\hline 13 & 6.99 & 150 & 0.45 & 46.67 & 2.27 & 0.29 & 0.20 \\
\hline 14 & 6.99 & 150 & 0.45 & 46.67 & 2.27 & 0.29 & 0.20 \\
\hline 15 & 6.99 & 150 & 0.45 & 46.67 & 2.27 & 0.29 & 0.20 \\
\hline 16 & 7.79 & 41 & 0.45 & 65.90 & 5.40 & 0.29 & 0.20 \\
\hline 17 & 7.79 & 41 & 0.45 & 65.90 & 5.40 & 0.29 & 0.20 \\
\hline 18 & 7.79 & 41 & 0.45 & 65.90 & 5.40 & 0.29 & 0.20 \\
\hline 19 & 8.64 & 38 & 0.46 & 109.33 & 3.92 & 0.30 & 0.20 \\
\hline 20 & 8.64 & 38 & 0.46 & 109.33 & 3.92 & 0.30 & 0.20 \\
\hline 21 & 8.64 & 38 & 0.46 & 109.33 & 3.92 & 0.30 & 0.20 \\
\hline 22 & 7.93 & 66 & 0.54 & 78.33 & 1.91 & 0.35 & 0.30 \\
\hline Median & 7.93 & 93 & 0.45 & 46.67 & 3.96 & 0.29 & 0.20 \\
\hline Std. dev. & 0.67 & 40 & 0.03 & 28.40 & 1.43 & 0.02 & 0.02 \\
\hline
\end{tabular}

The collected water quality data were analyzed using the statistical method of analysis of variance (ANOVA). ANOVA was 
performed separately for each plant for each of the water quality parameters monitored. The method measures the variance between the plant replicates, and it shows the degree of consistency between data. The null hypothesis $\left(\mathrm{H}_{0}\right)$ considered was that plant replicates performed consistently (no significant difference between the mean values). The $95 \%$ significance level (a) was used and the test statistic (F) was compared with the critical test statistic (Fcrit). For the non-normally distributed data, the analysis focused on the observations of median concentrations and standard deviations of water quality parameters for three replicates of each species. Table 3 provides the summary of the descriptive statistics of water quality data collected during the experiment. The computation was done using the Data Analysis tool of Microsoft Excel.

Table 3 Summary of descriptive statistics of water quality parameters.

\begin{tabular}{lccccccc}
\hline \multicolumn{1}{c}{ Statistics } & $\mathrm{pH}$ & $\begin{array}{c}\mathrm{ORP} \\
\mathrm{mV}\end{array}$ & $\begin{array}{c}\mathrm{EC} \\
\mathrm{mS} / \mathrm{cm}\end{array}$ & $\begin{array}{c}\mathrm{TB} \\
\mathrm{NTU}\end{array}$ & $\begin{array}{c}\mathrm{DO} \\
\mathrm{mg} / \mathrm{L}\end{array}$ & $\begin{array}{c}\mathrm{TDS} \\
\mathrm{g} / \mathrm{L}\end{array}$ & $\begin{array}{c}\mathrm{SL} \\
\mathrm{ppt}\end{array}$ \\
\hline Number of data & 264 & 264 & 264 & 264 & 264 & 264 & 264 \\
Mean & 7.768 & 144.8 & 1.279 & 0.950 & 4.702 & 0.824 & 0.647 \\
Median & 7.754 & 146.3 & 1.065 & 0 & 4.338 & 0.696 & 0.500 \\
Mode & 7.760 & 167.0 & 1.107 & 0 & 4.050 & 1.250 & 0.400 \\
Standard deviation & 0.398 & 34.28 & 0.631 & 5.502 & 1.221 & 0.406 & 0.342 \\
Sample variance & 0.159 & 1175 & 0.398 & 30.27 & 1.491 & 0.165 & 0.117 \\
Coefficient of Kurtosis & 0.129 & 3.031 & 6.525 & 76.83 & -0.261 & 6.035 & 6.695 \\
Coefficient of Skewness & 0.161 & 1.093 & 2.288 & 8.382 & 0.928 & 2.185 & 2.283 \\
Range & 2.230 & 222.3 & 3.862 & 59.90 & 4.702 & 2.515 & 2.100 \\
Minimum & 6.663 & 87.67 & 0.583 & 0 & 3.075 & 0.330 & 0.300 \\
Maximum & 8.893 & 310.0 & 4.445 & 59.90 & 7.777 & 2.845 & 2.400 \\
Confidence Level (95.0\%) & 0.048 & 4.154 & 0.076 & 0.667 & 0.148 & 0.049 & 0.041 \\
\hline
\end{tabular}

\section{Results and Discussions}

\section{$2.1 \mathrm{pH}$}

Figure 3 shows the median $\mathrm{pH}$ values of effluents from columns with different species. The results of ANOVA were the level of confidence $p(0.00)<a(0.05)$ and $F(9.449)>$ Fcrit (1.801), which suggest the rejection of the null hypothesis $\left(\mathrm{H}_{0}\right)$. Effluent $\mathrm{pH}$ values across the 12 species varied. However, no statistically significant variation was found (the null hypothesis was accepted) between the plant replicates: $\mathrm{p}(0.363)>a(0.05)$ and $F(1.014)<$ Fcrit (3.008). The median $\mathrm{pH}$ value (7.93) of the influent synthetic greywater was higher than the median effluent $\mathrm{pH}$ value (7.754). A similar result was found by Belmont and Metcalfe (2003). The plants with the lowest effluent $\mathrm{pH}$ performed well in reducing $\mathrm{pH}$ levels from the greywater. The species $A$. ficoidea, $C$. indica and $F$. nitida are in this category and they also have the lowest standard deviations. Consequently, these three plant species are not only the most effective, but also the most consistent among all the experimental plants. The species $P$. setaceum and $V$. agnus-castus also performed well in reducing $\mathrm{pH}$ levels, but they were inconsistent among the replicates.

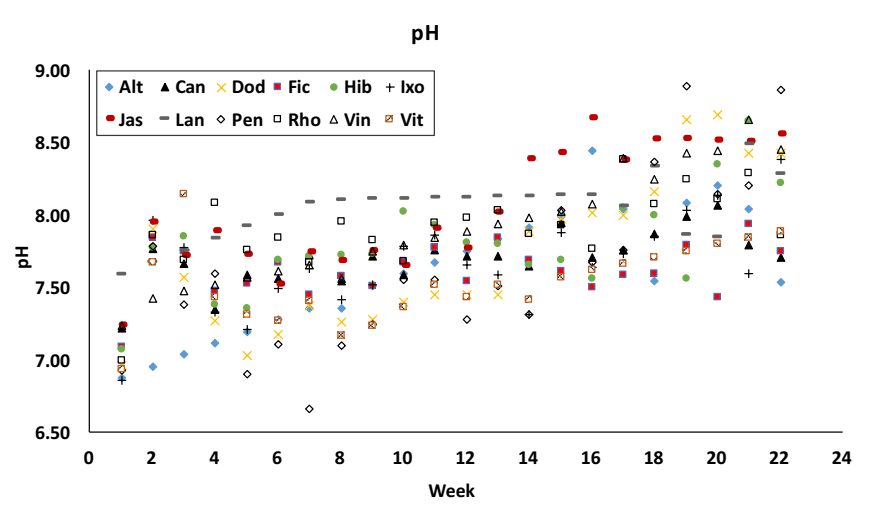

Figure $3 \mathrm{pH}$ of effluents over the period of the experiment.

\subsection{Conductivity}

Figure 4 shows the electrical conductivity (EC) levels of effluents throughout the experiment period. The species V. agnus-castus, $D$. viscosa and $P$. setaceum had high EC values at the beginning and at the end of the experiment. This trend was also observed in other parameters (except DO and ORP) and could be linked to the large body and root biomasses of the plants. A large body and root biomass allows a high evapotranspiration rate and subsequently affects the subsurface hydrology and pollutant concentrations in the effluent (Howard-Williams 1985). Figure 4 shows a seasonal change of EC values in effluent water, which can influence the nutrient uptake capacity of the plants (Tanner 2001). The species T. spathacea and F. nitida show the lowest median EC levels of $0.76 \mathrm{mS} / \mathrm{cm}$ and $0.87 \mathrm{mS} / \mathrm{cm}$ respectively, whereas $D$. viscos $a$ and $P$. setaceum exhibit the highest median levels of EC, $1.91 \mathrm{mS} / \mathrm{cm}$ and $1.87 \mathrm{mS} / \mathrm{cm}$ respectively. The species $H$. rosa-sinensis and $T$. spathacea show the lowest standard deviations, $0.021 \mathrm{mS} / \mathrm{cm}$ and $0.222 \mathrm{mS} / \mathrm{cm}$ respectively, whereas J. sambac and $P$. setaceum exhibit the highest standard deviations, $1.075 \mathrm{mS} / \mathrm{cm}$ and $0.971 \mathrm{mS} / \mathrm{cm}$ respectively. Unlike the $\mathrm{pH}$ trend (Figure 3), the effluent median EC level of 1.065 was found to be higher than the influent median EC level of $0.45 \mathrm{mS} / \mathrm{cm}$.

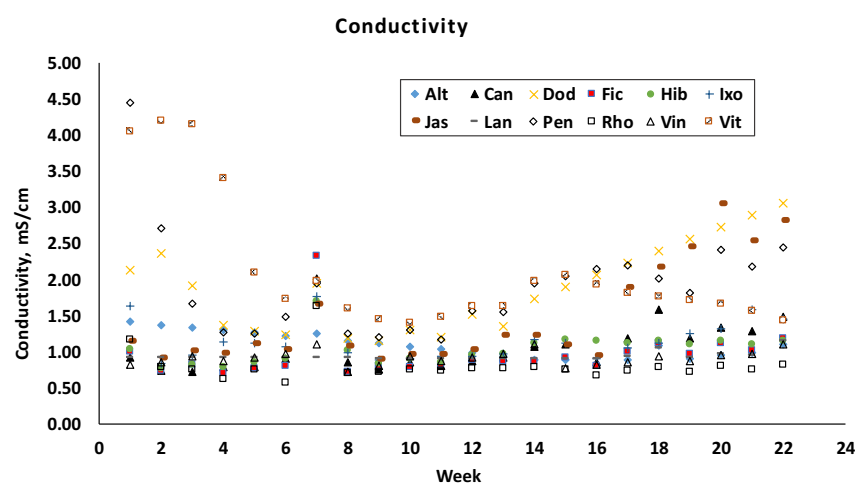

Figure 4 EC over the period of the experiment. 


\subsection{Dissolved Oxygen}

The DO levels from the columns of different plants are shown in Figure 5. It was found that $p(0.000)<a(0.05)$ and $F(7.360) \gg$ Fcrit (1.801) for the variation in DO levels between the plant species, which confirms that the mean DO values differ between species, so the null hypothesis $\mathrm{H}_{0}$ was rejected. Among the plant replicates, it was found that $p(0.191)>a(0.05)$ and $F(1.660)<$ Fcrit (3.008), which indicates that there is no statistically significant variation in DO levels between the plant replicates, so the null hypothesis $\mathrm{H}_{0}$ was accepted. The species $A$. ficoidea and $V$. rosea have the lowest median values of DO, $3.49 \mathrm{mg} / \mathrm{L}$ and $3.93 \mathrm{mg} / \mathrm{L}$ respectively, whereas $F$. nitida, I. coccinea and $C$. indica have the highest median DO levels, $5.33 \mathrm{mg} / \mathrm{L}, 4.80 \mathrm{mg} / \mathrm{L}$ and $4.64 \mathrm{mg} / \mathrm{L}$ respectively. The species $V$. agnus-castus and $C$. indica exhibit the least consistency among their replicates, having standard deviations $1.545 \mathrm{mg} / \mathrm{L}$ and $1.526 \mathrm{mg} / \mathrm{L}$ respectively, whereas A. ficoidea and D. viscosa have standard deviations $0.929 \mathrm{mg} / \mathrm{L}$ and $1.288 \mathrm{mg} / \mathrm{L}$ respectively. In general, the level of DO rises as the weather becomes colder (December through February); a similar phenomenon was observed by Belmont and Metcalfe (2003). The results mostly show the influence of plants on DO levels since the extent at which oxygen is lost from plants depends on the anatomical properties of the root (Sorrell et al. 2000) and the intensity of oxygen consumption in the rhizosphere (Sorrell and Armstrong 1994).

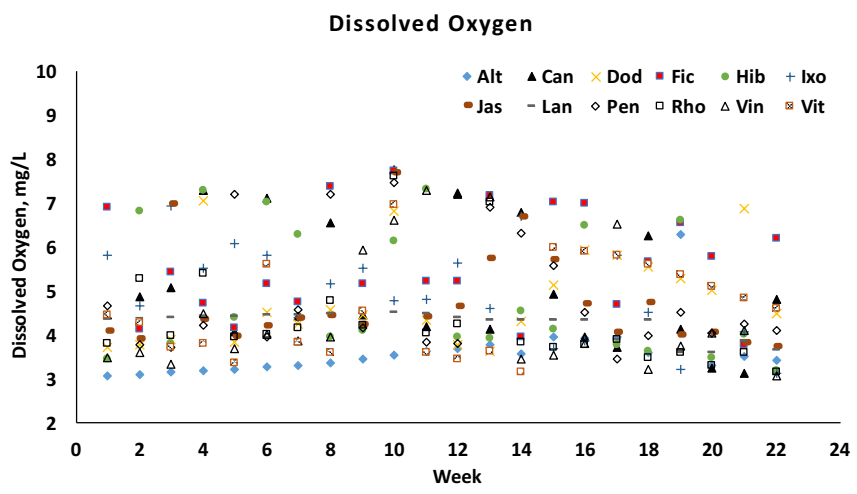

Figure 5 DO over the period of the experiment.

\subsection{Total Dissolved Solids}

Figure 6 shows the TDS levels from the columns. The TDS concentrations vary significantly among the plant species. The trends at the beginning and at the end of the study are similar to those of EC (Figure 4 above); there is a positive correlation between EC and TDS. The species T. spathacea and F. nitida have the lowest median values of TDS, $0.49 \mathrm{~g} / \mathrm{L}$ and $0.56 \mathrm{~g} / \mathrm{L}$ respectively, whereas $P$. setaceum and $D$. viscosa exhibit the highest median values of TDS, $1.21 \mathrm{~g} / \mathrm{L}$ and $1.22 \mathrm{~g} / \mathrm{L}$ respectively. The highest standard deviations, $0.677 \mathrm{~g} / \mathrm{L}$ and $0.648 \mathrm{~g} / \mathrm{L}$, were observed for J. sambac and $V$. agnus-castus respectively, and the lowest standard deviations were observed in $H$. rosa-sinensis $(0.136 \mathrm{~g} / \mathrm{L})$ and $T$. spathacea $(0.142 \mathrm{~g} / \mathrm{L})$, making the latter two species the most consistent in terms of TDS levels. The median TDS concentration in synthetic greywater was $0.29 \mathrm{~g} / \mathrm{L}$, whereas in the effluents it was $\sim 0.696 \mathrm{~g} / \mathrm{L}$, an increase of $>50 \%$. This strongly suggests that a substantial quantity of solids was dissolved and washed out of the biofiltration system.

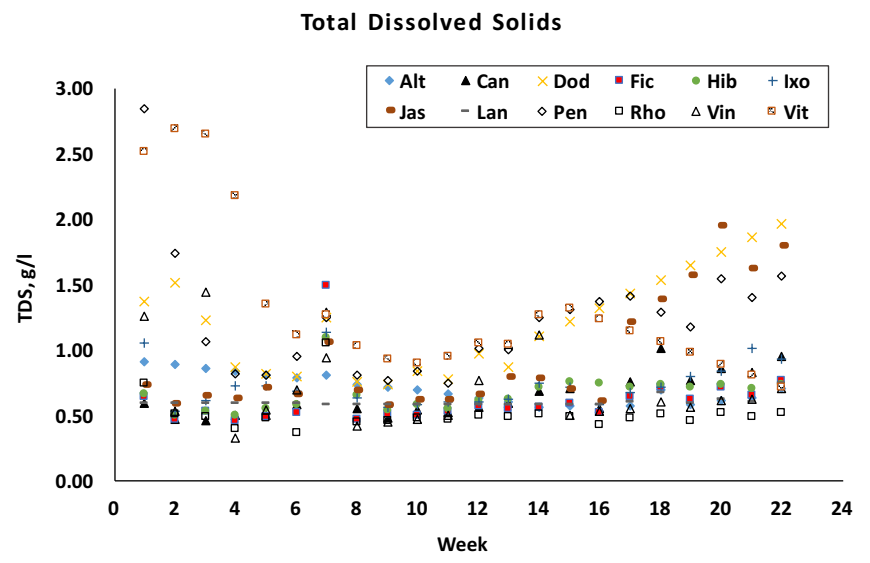

Figure 6 TDS over the period of the experiment.

\subsection{Oxidation Reduction Potential}

Figure 7 shows the ORP values in the effluents. A decreasing trend is observed in Figure 7. Some species (P. setaceum, F. nitida, C. indica, J. sambac, T. spathacea) show a relatively high level of ORP in week 2 and a few species (F. nitida, l. coccinea, P. setaceum) in week 11 of the experiment. Other than these species, all the species follow a same pattern of change. It is worth noting that there exists a minimum ORP value of $88 \mathrm{mV}$ in almost all the effluent samples shown in Figure 7, which is almost equal to the median ORP value (93 mV) of the synthetic greywater used in the experiment (Table 2 above). The species $A$. ficoidea and $V$. agnus-castus were identified as the most consistent plant species, having standard deviations $27.53 \mathrm{mV}$ and $28.92 \mathrm{mV}$ respectively. The least consistent plants were $P$. setaceum and F. nitida, with standard deviations $46.08 \mathrm{mV}$ and $43.48 \mathrm{mV}$ respectively.

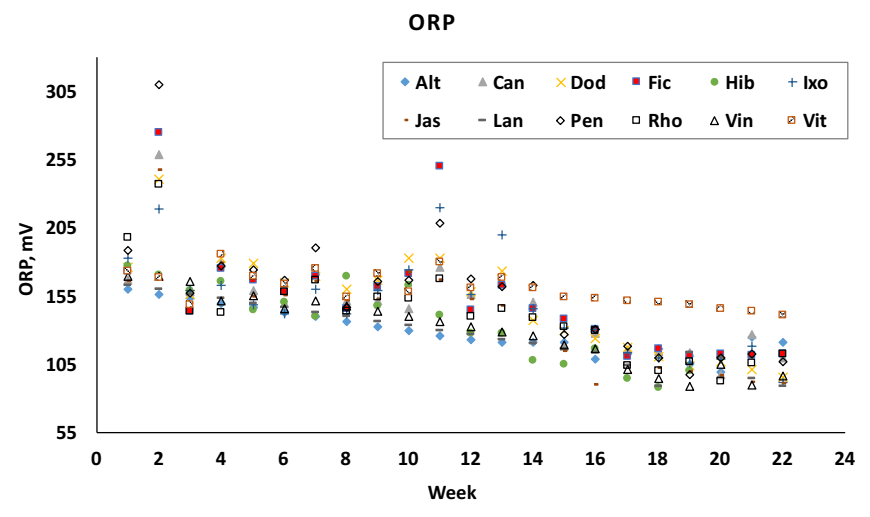

Figure 7 ORP over the period of the experiment. 


\subsection{Salinity}

Figure 8 illustrates the variations of salinity in the effluents during the period of the study. Since there is a positive correlation between salinity, conductivity and TDS, the salinity variations exhibit a similar pattern of EC (Figure 4) and TDS (Figure 6).The columns containing $V$. agnus-castus and $D$. viscosa exhibit the highest mean values of salinity, 1.065 ppt and 0.945 ppt respectively, whereas the lowest mean values, 0.410 ppt and 0.482 ppt, were observed in columns containing T. spathacea and F. nitida respectively. The species $A$. ficoidea (standard deviation 0.09 ppt) and T. spathacea (standard deviation $0.113 \mathrm{ppt}$ ) were found to be the most consistent plant replicates. On the other hand, J. sambac (standard deviation $0.581 \mathrm{ppt}$ ) and $P$. setaceum (standard deviation $0.543 \mathrm{ppt}$ ) were observed to be the least consistent. The median salinity concentration, $0.20 \mathrm{ppt}$, in the synthetic greywater (Table 2) was found in most cases to be lower than the effluent concentration, which is within the range 0.30 ppt to $2.40 \mathrm{ppt}$ (median value $0.5 \mathrm{ppt}$ ). The increased salinity in effluent water is probably a result of dissolution from the media used in the columns.

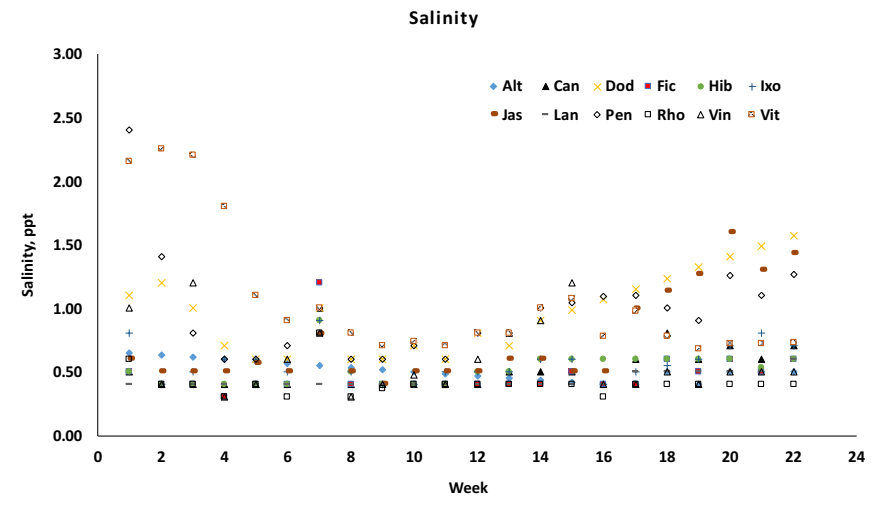

Figure 8 Salinity over the period of the experiment.

\subsection{Turbidity}

Among all the plants and all the replicates, the turbidity was found to be zero between week 6 and week 15 of the experiment (Figure 9). Differences in turbidity were mainly observed at the beginning and at the end of the experiment; during both of these periods there were similar weather conditions. The columns containing $A$. ficoidea and $L$. camara show a turbidity level of zero almost entirely throughout the experimental period. The columns containing F. nitida and $C$. indica had the lowest turbiidity values, 0.4 NTU and 0.7 NTU respectively, whereas the columns containing $V$. agnus-castus and $V$. rosea had the highest turbidity values, 4.1 NTU and 7.65 NTU respectively. The lowest standard deviations, 0.287 NTU and 1.201 NTU, were observed for F. nitida and $I$. coccinea respectively, making them the most consistent plants in terms of turbidity reduction. The highest standard deviations, 20.546 NTU and 5.621 NTU, were observed for V. agnus-cas- tus and $V$. rosea respectively, making them the most inconsistent species in terms of their turbidity reduction efficiency.

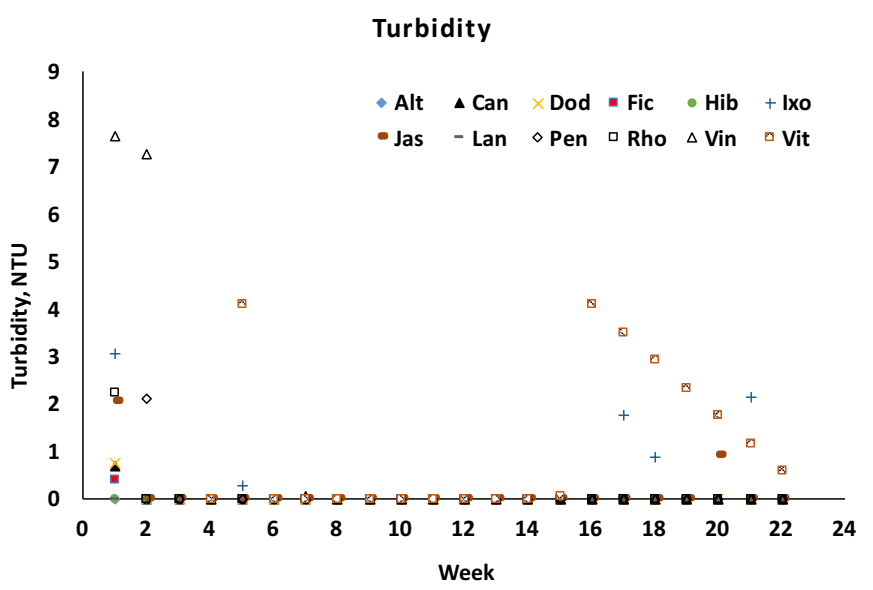

Figure 9 Turbidity over the period of the experiment.

\section{Conclusion}

This study investigated the ability of twelve ornamental plant species to improve greywater quality in vegetative biofiltration columns. Several observations were made during the experimental period. While T. spathacea was not found to be stressed with less irrigation water, other plants, such as $C$. indica, needed a little more water in order to stay healthy. Interestingly, some other plants, such as $V$. agnus-castus and $D$. viscosa, were observed to be able to tolerate both the drought conditions (preferred by T. spathacea) and the wet conditions (preferred by C. indica). The ability of the plants to influence greywater quality in the biofiltration prototypes differs from species to species. Among the plants used, those with a smaller root and body mass ( $15 \mathrm{~cm}$ root depth over the 8 month culture) exerted a greater effect on the effluent quality than those with greater root depth and larger body mass. The behaviour of the water quality parameters during the period of the experiment varies. While $\mathrm{pH}$ increases over time, a seasonal pattern is observed for dissolved oxygen.

This laboratory scale experiment does not give the most accurate results for biofiltration, although it gives an idea of the trend. A further field study must be conducted to obtain better representative data values for the water quality parameters measured in this work as well as others mentioned in the literature. In addition, plants with higher biomass in the roots and the stems could be studied separately as their water consumption, particularly in arid climates, differs from those with less biomass. The efficiency of heavy metal and nutrient removal is also important and must be considered in the selection of the most appropriate plants for greywater biofiltration systems in arid regions. It is under investigation as an extension of this study. 


\section{Acknowledgment}

The study is supported by the UAEU National Water Center interdisciplinary research grant (31R045-Research Center-NWC -2-2014) titled Greywater Reuse in Arid Climate through the Water Sensitive Urban Design Systems.

\section{References}

Belmont, M. A. and Metcalfe, C. D. 2003. "Feasibility of Using Ornamental Plants (Zantedeschia aethiopica) in Subsurface Flow Treatment Wetlands to Remove Nitrogen, Chemical Oxygen Demand and Nonylphenol Ethoxylate Surfactants-A Laboratory-Scale Study." Ecological Engineering 21:233-47.

Blick, S. A., F. Kelly and J. J. Skupien. 2004. New Jersey Stormwater Best Management Practices Manual. Trenton, NJ: State of New Jersey Department of Environmental Protection.

Chowdhury, R. K. 2015. "Greywater Reuse Through a Bioretention System Prototype in the Arid Region." Water Science and Technology 72 (12): 2201-11.

Chowdhury, R. K., W. El-Shorbagy, M. Ghanma and A. El-Ashkar. 2015. "Quantitative Assessment of Residential Water End Uses and Greywater Generation in the City of Al Ain." Water Science and Technology: Water Supply 15 (1): 114-23.

Chowdhury, R. K. and M. A. Rajput. 2017. “Will Greywater Reuse Really Affect the Sewer Flow? Experience of a Residential Complex in Al Ain, UAE." Water Science and Technology: Water Supply: 17 (1): 246-58.

Davis, A. P., M. Shokouhian, H. Sharma and C. Minami. 2006. "Water Quality Improvement Through Biofiltration Media: Nitrogen and Phosphorus Removal." Water Environment Research 78 (3): 284-93.

Endreny, T. and V. Collins. 2009. "Implications of Biofiltration Basin Spatial Arrangements on Stormwater Recharge and Groundwater Mounding." Ecological Engineering 35:670-7.

Fowdar, H.S., B.E. Hatt, T. Cresswell, J.J. Harrison, P.L.M. Cook and A. Deletic. 2017. "Phosphorus fate and dynamics in greywater biofiltration systems." Environmental Science and Technology 51 (4): 2280-2287.

Henderson, C., M. Greenway and I. Phillips. 2007. "Sorption Behaviour of Nutrients in Loamy-Sand Bioretention Media Subject to Different Conditions (Vegetation, Enrichment and Incubation Time)." Presented at the Conference on Rainwater and Urban Design, Sydney, Australia, 21-23 August, 2007.

Howard-Williams, C. 1985. “Cycling and Retention of Nitrogen and Phosphorus in Wetlands: A Theoretical and Applied Perspective." Freshwater Biology 15 (4): 391-431.

Kazemi, F., S. Beecham and J. Gibbs. 2009. "Streetscale Bioretention Basins in Melbourne and Their Effect on Local Biodiversity." Ecological Engineering 35:1454-65.
Langergraber, G. 2005. "The Role of Plant Uptake on the Removal of Organic Matter and Nutrients in Subsurface Flow Constructed Wetlands: A Simulation Study." Water Science and Technology 51 (9): 213-23.

Li, F., K. Wichmann and R. Otterpohl. 2009. "Review of the Technological Approaches for Grey Water Treatment and Reuses." Science of the Total Environment 407:3439-49. https://doi.org/10.1016/j.scitotenv.2009.02.004

Li, Z., H. Gulyas, M. Jahn, D. R. Gajurel and R. Otterpohl. 2003. "Greywater Treatment by Constructed Wetland in Combination with $\mathrm{TiO}_{2}$-Based Photocatalytic Oxidation for Suburban and Rural Areas Without Sewer System." Water Science and Technology 48 (11): 101-6.

Paulo, P. L., C. Azevedo, L. Begosso, A. F. Galbiati and M. A. Boncz. 2013. "Natural Systems Treating Greywater and Blackwater On-Site: Integrating Treatment, Reuse and Landscaping." Ecological Engineering 50:95-100.

Prodanovic, V., B. Hatt,D., McCarthy, K. Zhang and A. Deletic. 2017. "Green Walls for Greywater Reuse: Understanding the Role of Media on Pollutant Removal." Ecological Engineering 102:625-35.

Sorrell, B. K. and W. Armstrong. 1994. "On the Difficulties of Measuring Oxygen Release by Root Systems of Wetland Plants." Journal of Ecology 82:177-83.

Sorrell, B. K., I. A. Mendelssohn, K. L. McKee and R. A. Woods. 2000. “Ecophysiology of Wetland Plant Roots: A Modelling Comparison of Aeration in Relation to Species Distribution." Annals of Botany 86 (3): 675-85.

Tanner, C. C. 2001. "Plants as Ecosystem Engineers in Subsurface-Flow Treatment Wetlands." Water Science and Technology 44 (11-12): 9-17.

Trowsdale, S. A and R. Simcock. 2011. “Urban Stormwater Treatment Using Bioretention." Journal of Hydrology 397 (3): 167-74.

Vymazal, J. 2011a. "Constructed Wetlands for Wastewater Treatment: Five Decades of Experience." Environmental Science \& Technology 45:61-9.

Vymazal, J. 2011 b. “Plants Used in Constructed Wetlands with Horizontal Subsurface Flow: A Review." Hydrobiologia 674 (1): 133-56.

Wong, T. H. F. 2006. "An Overview of Water Sensitive Urban Design Practices in Australia." Water Practice \& Technology: 1 (1). https://doi.org/10.2166/WPT.2006018

Woods-Ballard, B., R. Kellagher, P. Martin, C. Jefferies, R. Bray and P. Shaffer. 2007. The SuDS Manual. London: Ciria. C697. https://www.ciria.org/Resources/Free_publications/SuDS_ manual_C753.aspx?WebsiteKey=3f18c87a-d62b-4eca-8ef4 $-9 b 09309 c 1 c 91$ 